Article

\title{
Enhanced Wear Resistance of the Ultrastrong Ultrasonic Shot-Peened M50 Bearing Steel with Gradient Nanograins
}

\author{
Zhaohua Dong ${ }^{1,2,3, \dagger}{ }^{\text {, Feng Wang }}{ }^{2,3,+}$, Dongsheng Qian ${ }^{1,2,3, * \oplus \text {, Fei Yin }}{ }^{2,3, *}$, Huiling Wang ${ }^{1,2,3}$, \\ Xiaokang Wang ${ }^{4}\left(\mathbb{D}\right.$, Shan $\mathrm{Hu}^{4}$ and Jie Chi ${ }^{5}$
}

check for

updates

Citation: Dong, Z.; Wang, F.; Qian, D.; Yin, F.; Wang, H.; Wang, X.; Hu, S.; Chi, J. Enhanced Wear Resistance of the Ultrastrong Ultrasonic

Shot-Peened M50 Bearing Steel with Gradient Nanograins. Metals 2022, 12 424. https://doi.org/10.3390/ met12030424

Academic Editor: Ayrat Nazarov

Received: 30 January 2022

Accepted: 19 February 2022

Published: 28 February 2022

Publisher's Note: MDPI stays neutral with regard to jurisdictional claims in published maps and institutional affiliations.

Copyright: (C) 2022 by the authors. Licensee MDPI, Basel, Switzerland. This article is an open access article distributed under the terms and conditions of the Creative Commons Attribution (CC BY) license (https:// creativecommons.org/licenses/by/ $4.0 /)$.
1 School of Materials Science and Engineering, Wuhan University of Technology, Wuhan 430070, China; dongzhaohua@whut.edu.cn (Z.D.); wangh191721@whut.edu.cn (H.W.)

2 Hubei Key Laboratory of Advanced Technology for Automotive Components, Wuhan 430070, China; wangfengwut@whut.edu.cn

3 Hubei Engineering Research Center for Green Precision Material Forming, Wuhan 430070, China

4 School of Mechanical Engineering, Purdue University, West Lafayette, IN 47907, USA; wang3752@purdue.edu (X.W.); shan17@purdue.edu (S.H.)

5 Aero Engine Corporation of China Harbin Bearing Co., Ltd., Harbin 150500, China; chijie0123@163.com

* Correspondence: qiands@whut.edu.cn (D.Q.); fyin@whut.edu.cn (F.Y.); Tel.: +86-2787505177 (D.Q.)

+ These authors contributed equally to this work.

\begin{abstract}
The enhancement of the wear resistance has long been important for bearing steels, hampered in part by the lack of suitable surface strengthening techniques. In this study, ultrasonic shot peening (USP) is employed to enhance the wear resistance of the M50 bearing steel by generating an ultrastrong surface layer with gradient nanograins. The effects of USP treatment on the surface integrity, microstructures, and wear behavior of M50 steel are investigated. The microstructural observation shows that the gradient nanograined surface layer is over $200 \mu \mathrm{m}$ thick. The lath martensite is refined to nano-martensitic subgrains with few low angle boundaries in the USP-treated M50 steel. Additionally, the microhardness of the nanostructured M50 steel is increased from $795 \mathrm{HV}$ to $987 \mathrm{HV}$ with a penetrating depth of around $800 \mu \mathrm{m}$. Wear tests show that the wear rate of the USP-treated M50 steel is reduced by $50.4 \%$ under sliding conditions compared to that of the untreated samples. The significantly enhanced wear resistance of the USP-treated M50 is attributed to the ultrastrong gradient nanograined surface layer. The wear mechanism of the USP-treated M50 steel changes from oxidative wear and severe plowing wear to mild plowing wear. Additionally, the thickness of the plastic deformation layer generated during the friction process is reduced. This work provides the materials scientists and engineers with an efficient surface treatment method to enhance the wear resistance of high-strength steels.
\end{abstract}

Keywords: ultrasonic shot peening; wear behavior; lath martensite; microhardness; M50 steel

\section{Introduction}

The bearings applied on aeroengine shafts are required to serve under vibration stresses, high rotational speeds, and aggressive lubrication, etc. [1]. Among the steels for aerospace bearings, M50 steel is widely used because of its excellent dimensional stability and hardness retention in high-temperature environments [2]. As bearings inevitably suffer from wear during operation, wear failure caused by surface abrasion is one of the main failure modes for aerospace bearings [3]. Therefore, it is necessary to explore a surface strengthening technique to effectively improve the wear resistance of M50 steel.

Surface nitriding and alloying techniques have been widely employed to improve the wear properties of metal alloys [4-6]. However, these techniques are costly and usually performed at high temperatures, which may compromise the service life of metallic materials. In terms of the mechanical surface-strengthening process, shot peening (SP) is a typical and generally accepted method [7]. SP can lead to plastic deformation and 
work hardening of the material surface through the constant impact of high-speed shots [8]. Residual compressive stresses are introduced in the surface layer of the material after shot peening, which enhances the wear resistance, stress corrosion resistance, and fatigue resistance of the bearings [9]. Generally, bearing parts need to have good surface accuracy to maintain their long-term operation $[10,11]$. However, SP reduces the surface quality of the material and affects the lubrication state of the in-service tribological components inside the bearing, which is detrimental to the fatigue life [12]. Therefore, SP cannot be applied to high-precision bearing products owing to its deterioration in surface roughness. If the subsequent superfinishing process is performed, then the limited strengthening layer will be removed. These disadvantages render SP a poor strengthening method for the bearing materials since they must have a tough core and a hard surface to retard the initiation of cracks against fatigue and wear failures $[13,14]$. Laser shock impact treatment is also an effective method of surface strengthening due to its minimal effect on surface accuracy [15]. However, laser shock impact treatment can not provide a deep enough strengthening layer, so its application on aerospace bearings may be difficult [16].

The USP treatment is suitable for application to bearings because a gradient nanostructured surface layer with a spatially graded microstructure from nanometers to microns could be obtained $[17,18]$. The sufficiently deep strengthening layer provides opportunities for the application of USP on aerospace bearings. Based on traditional shot peening, USP uses ultrasonic vibrational energy to drive the shots to fly within the chamber, impacting the exposed sample surface and thus strengthening the material surface. USP has the advantages of low energy consumption, low pollution, short processing time, strong controllability of process parameters, and wide application $[19,20]$. Chen et al. reported that a grain-refined strengthening layer with grain sizes of less than $10 \mathrm{~nm}$ could be obtained on a pure copper surface layer by employing USP [21]. With the increase of surface strain during USP treatment, various microstructures such as dislocation sources, dislocation cells, and nanostructures are generated in the surface grains, leading to the separation of grains into nanoscale subgrains $[22,23]$. The nanocrystalline structures induced by USP have many positive effects. For example, high residual compressive stress [24] and surface hardness [25] after USP treatment improve the fatigue resistance [26] and corrosion resistance [27]. Besides, higher wear resistance under sliding conditions is also observed in some alloys due to the increased hardness and residual stress on the surface [28]. Previous studies have confirmed the significant improvement of surface mechanical properties of metal alloys by USP. However, no systematic study investigating the role of USP treatment on the surface integrity, microstructure development, and wear behavior for bearing steels has been published to date.

In this work, the effects of USP on the changes of surface roughness, microstructure, hardness, residual stress, and wear resistance of M50 steel have been investigated. The evolutionary behavior of microstructure and dry sliding wear mechanism of the surface layer of M50 steel after USP treatment are discussed in detail.

\section{Materials and Methods}

\subsection{Materials}

The M50 bearing steel used in this study is a $\Phi 70 \mathrm{~mm}$ bar received in the annealed state. The composition of the material is provided in Table 1 . The bar was cut into $5 \mathrm{~mm}$ thick plates by wire electrical discharge machining, followed by quenching and tempering (QT) heat treatment: firstly, the plates were held in a vacuum furnace (WZGQ-30) at $1090{ }^{\circ} \mathrm{C}$ for $25 \mathrm{~min}$, then quenched in oil at $60{ }^{\circ} \mathrm{C}$, and finally, three successive high temperature tempering at $530{ }^{\circ} \mathrm{C}$ for $2 \mathrm{~h}$. The samples with dimensions of $28 \mathrm{~mm} \times 28 \mathrm{~mm} \times 4 \mathrm{~mm}$ were mechanically polished with 320-2000 grit SiC sandpapers and $1 \mu \mathrm{m}$ diamond suspension in preparation for the USP treatment. 
Table 1. Chemical compositions of M50 bearing steel (wt.\%).

\begin{tabular}{ccccccc}
\hline $\mathbf{C}$ & $\mathbf{C r}$ & Mo & V & Mn & W & Fe \\
\hline $0.8-0.85$ & $4-4.25$ & $4-4.5$ & $0.9-1.1$ & $0.15-0.35$ & $\leq 0.25$ & Bal. \\
\hline
\end{tabular}

Electron back-scattered diffraction (EBSD) was used to investigate the microstructure of the M50 matrix. Figure 1 shows the inverse pole figure (IPF) map, grain boundary map, and kernel average misorientation (KAM) map of the matrix of M50 after QT heat treatment. The main microstructure of M50 is martensite with an average grain size of $1.83 \mu \mathrm{m}$ (Figure 1a,d). In the grain boundary map, red lines stand for the low angle boundaries (LABs) with misorientation $2-15^{\circ}$, while blue lines indicate the high angle boundaries (HABs) with misorientation $>15^{\circ}$. The statistical results show that the content of LABs of the M50 matrix is $17.2 \%$. The KAM map reflects the strain history and dislocation density of the materials in different regions. The red points in the KAM map indicate high plastic strain, blue points indicate low plastic strain, and white points represent alloy carbides in M50. The high and low plastic strains are uniformly distributed in the M50 steel matrix with an average KAM degree of $2.21^{\circ}$.
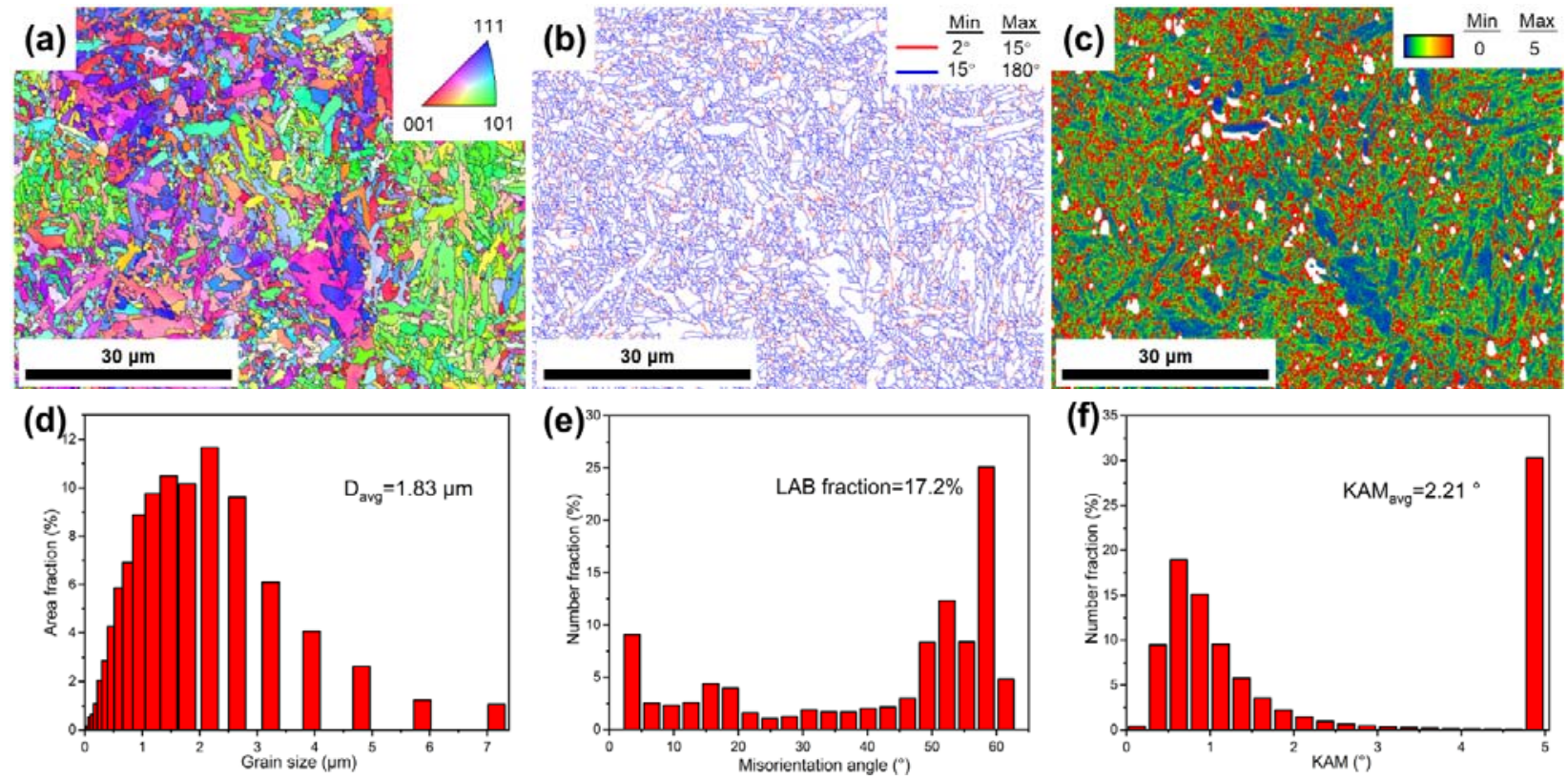

Figure 1. EBSD results of M50 matrix after QT heat treatment: (a) IPF map; (b) grain boundary map; (c) KAM map; (d-f) statistical results of $(\mathbf{a}-\mathbf{c})$, respectively.

\subsection{USP Treatment}

The USP treatment was applied with homemade equipment, and the schematic diagram is shown in Figure 2a. The equipment is mainly composed of the ultrasonic generator, the transducer, the sonotrode, the chamber, and shots. In this study, the power of the ultrasonic generator was fixed at $1.5 \mathrm{~kW}$, the WC balls with a diameter of $4 \mathrm{~mm}$ were used as shots, and the USP processing durations were $1 \mathrm{~min}, 5 \mathrm{~min}$, and $10 \mathrm{~min}$. The surface status of the sample after 10 min of USP treatment is shown in Figure 2b. The treated area is obviously rougher. 

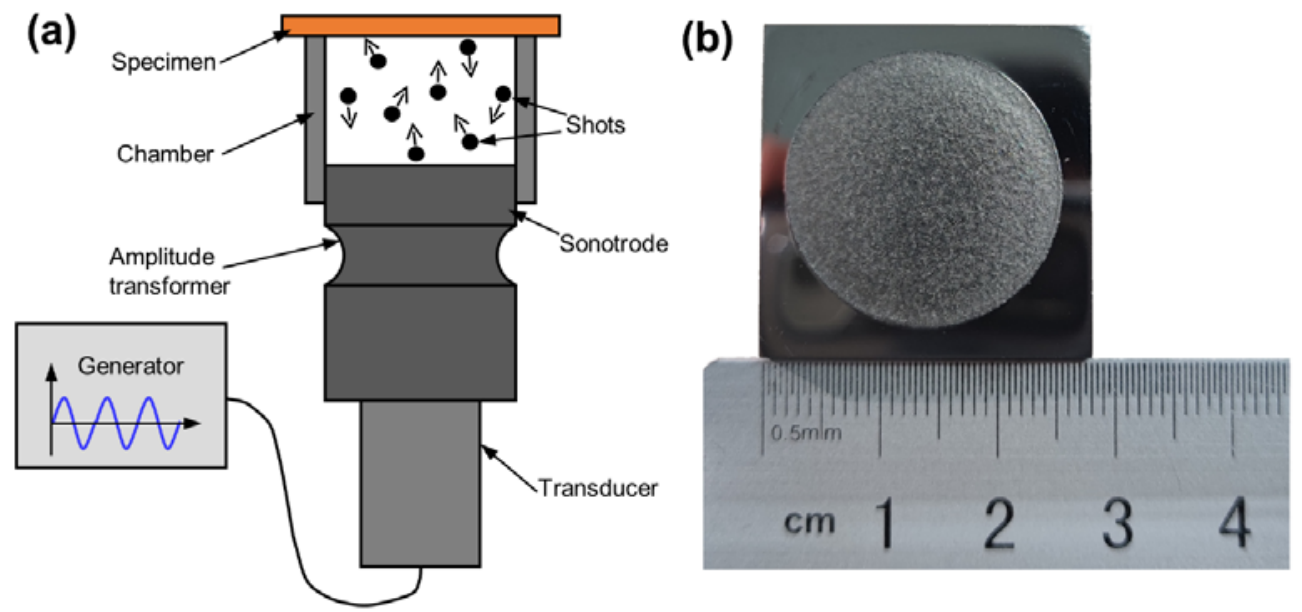

Figure 2. (a) Schematic diagram of the USP equipment; (b) surface status of the sample after USP treatment for $10 \mathrm{~min}$.

\subsection{Materials Characterizations}

The confocal laser scanning microscopy (LSM 800, Zeiss, Oberkochen, Germany) was used to measure the surface roughness of samples with different USP treatment durations. The software (ConfoMap ${ }^{\circledR}$ ST, Zeiss, Oberkochen, Germany) was used to analyze the surface topography. No filters were applied in this work. The X-ray diffraction (XRD) data were obtained with a scanning speed of $1^{\circ} / \mathrm{min}$ on a diffraction analyzer (D/MAXRB, Rigaku, Tokyo, Japan). SEM and EBSD were used to characterize the cross-sectional microstructure changes, including grain size, dislocation density, and grain boundaries. The scan step of EBSD is set to $90 \mathrm{~nm}$ to ensure the validity of the data. TEM tests were performed by a field emission transmission electron microscope (Tecnai G2 F30, FEI, Hillsboro, OR, USA) to reveal the influence mechanism of USP on the microstructure of M50. The Vickers hardness of each sample was measured by a microhardness tester (HVT-1000A, Huayin, Laizhou, China) held at a loading force of $1000 \mathrm{~g}$ for $10 \mathrm{~s}$. To prevent inaccurate data of surface hardness, the depth distribution of Vickers hardness was measured by the peeling method. The surface of the samples was ground with sandpapers, and the thickness is reduced by $25-50 \mu \mathrm{m}$ layer by layer. For each grinding layer, 5 points were measured randomly and the average value was taken as the Vickers hardness of the layer.

\subsection{Wear Tests}

UMT-2 multifunctional friction and wear tester was employed to perform pin-on-disk (POD) testing to evaluate the effect of USP treatment durations on the dry sliding wear resistance of $\mathrm{M} 50$ bearing steel. The $\mathrm{Al}_{2} \mathrm{O}_{3}$ balls of $10 \mathrm{~mm}$ in diameter were used as the pin. The POD tests were conducted at a speed of $360 \mathrm{rpm}(0.188 \mathrm{~m} / \mathrm{s})$ under a load of $50 \mathrm{~N}$ at $300{ }^{\circ} \mathrm{C}$ for $3600 \mathrm{~s}$. The friction coefficient was obtained by real-time monitoring of the friction force sensor. After wear tests, the wear scars were observed by a surface profiler (MMD-HPG120, Wilson, Guangzhou, China) to obtain the wear volume. To quantify the wear resistance, the wear rate is calculated according to Archard's classical wear formula [29]:

$$
\mathrm{W}=\Delta V /(N \cdot L)
$$

where $N, L$, and $\Delta V$ denote the load, sliding distance, and wear volume, respectively. The wear tests were performed three times for each test condition to ensure the reproducibility of the experimental data. The wear morphology of the samples was analyzed by SEM after wear tests. In addition, the cross-sectional microstructure of the wear track was characterized by SEM. 


\section{Results}

\subsection{Surface Roughness}

The surface quality of the bearing is very important to the friction performance and fatigue life. Figure 3 shows the surface topography of M50 steel after different USP treatment durations. The sample before the USP treatment has a smooth surface with a Sa of $0.024 \mu \mathrm{m}$. After USP treatment, the surface of M50 steel is subjected to the high-speed impact of shots and undergoes violent plastic deformation. As shown in Figure $3 b-d$, the surface of M50 steel after USP treatment has many pits and peaks, and the increase of surface roughness is obvious. Meantime, the maximum surface profile height and surface roughness tend to increase with the USP treatment duration (from Sa $2.53 \mu \mathrm{m}$ at $1 \mathrm{~min}$ to Sa $3.31 \mu \mathrm{m}$ at $10 \mathrm{~min})$.

(a)

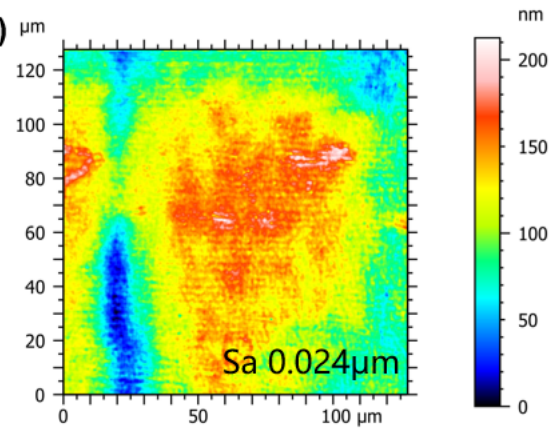

(c)

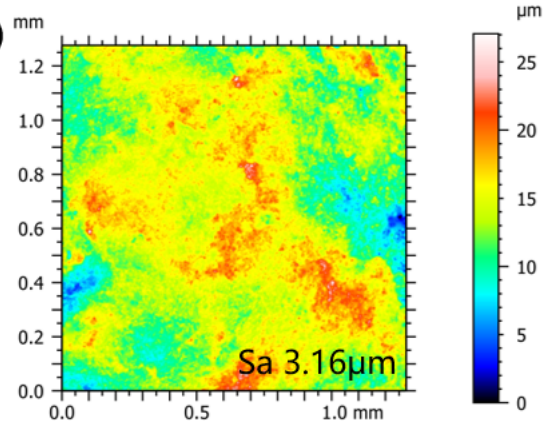

(b)

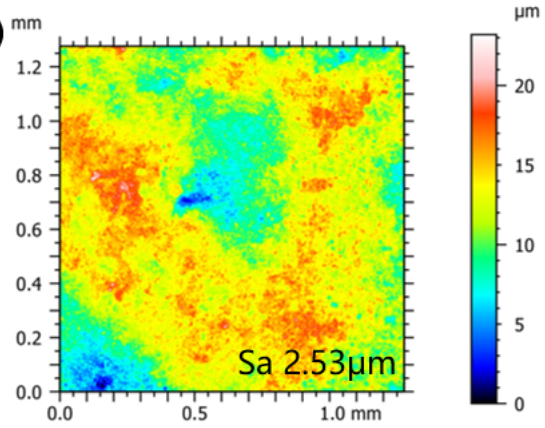

(d)

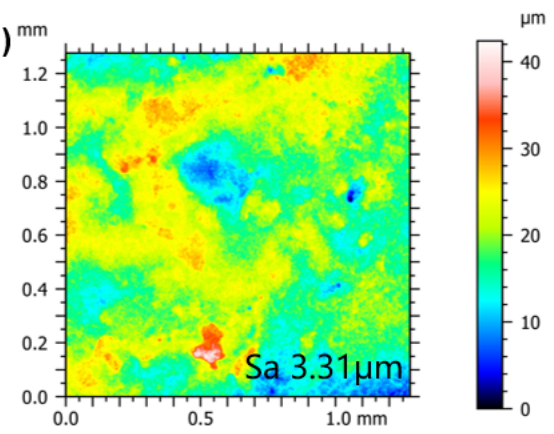

Figure 3. Images of the surface morphology for the M50 steel with different USP durations: (a) 0 min; (b) $1 \mathrm{~min}$; (c) $5 \mathrm{~min}$; (d) $10 \mathrm{~min}$.

\subsection{X-ray Diffractograms}

Figure 4 illustrates the surface XRD patterns of M50 steel treated by USP with different treatment durations. In Figure $4 \mathrm{a}$, the main composition of M50 steel without USP treatment is martensite with diffraction peaks $(110)_{\alpha},(200)_{\alpha},(211)_{\alpha}$ and $(220)_{\alpha}$. After the USP treatment, the diffraction peaks have no significant changes compared to the untreated ones, indicating that no new phase is formed. After USP treatment, the $(200)_{\alpha},(211)_{\alpha}$, and $(220)_{\alpha}$ peaks of martensite shift to lower diffraction angles (Figure $4 b-d$ ), which may be related to the tensile/compressive residual stress and crystal orientation caused by plastic deformation [30]. At the same time, the peak widths for each peak have been gradually widened with the increase of USP treatment duration. The broadening of diffraction peaks can be explained by Scherrer's formula [31].

$$
D=k \lambda / \beta \cos \theta
$$

where $D$ is the average grain size, $k$ the Scherrer constant, $\lambda$ the wavelength of the $\mathrm{X}$ ray $(1.5406 \mathrm{~nm}), \beta$ the FWHM value, and $\theta$ the Bragg angle for the peak. The equation demonstrates that the smaller the average grain size of the material, the broader the X-ray diffraction peak. Therefore, the X-ray diffraction results show that the USP treatment has a significant effect on the grain refinement of the surface layer of M50 steel. 

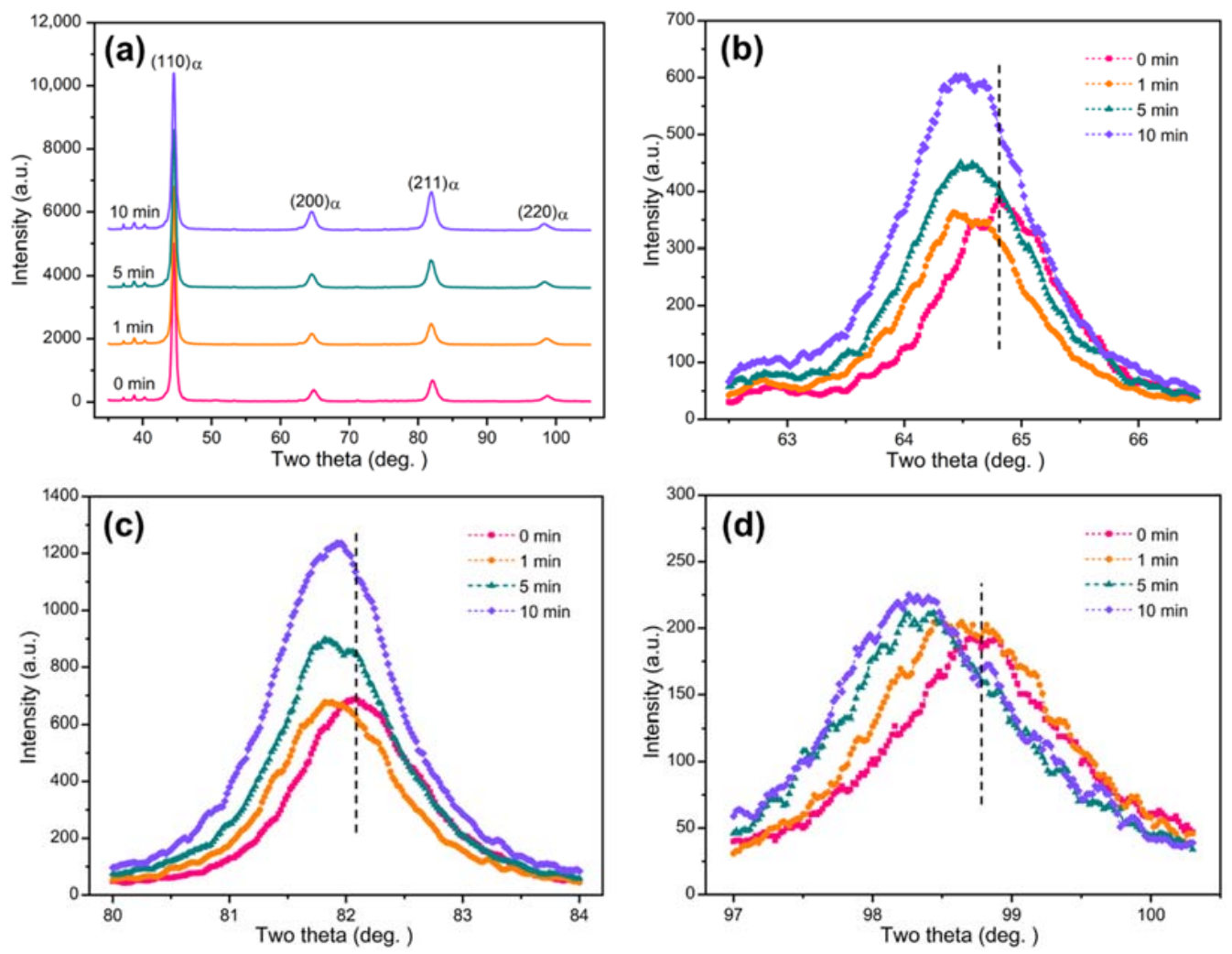

Figure 4. (a) XRD patterns of the M50 steel with different USP durations; (b) (200) $\alpha$ peak; (c) (211) $\alpha$ peak; (d) (220) $\alpha$ peak.

\subsection{Gradient Nanograined Structure}

Figure 5 shows the SEM micrographs of the cross-sectional microstructure of the M50 steel with different USP durations. Before USP treatment, the microstructure of M50 steel consists of lath martensite and undissolved alloy carbides (Figure 5a). Almost no retained austenite exists, which is consistent with the results of XRD. After USP treatment, the lath martensite has been refined evidently. With the increase of USP treatment duration, the martensitic refinement effect becomes more pronounced, and the phase interface gets blurred (Figure 5d). At the same time, the lath martensite near the surface layer of M50 steel is gradually distorted due to the accumulated plastic deformation under the continuous impact of shots. Inevitably, with the increase of surface roughness, the impact of highenergy shots also causes delamination in the surface layer. No significant changes were observed for the alloy carbides distributed in the matrix.
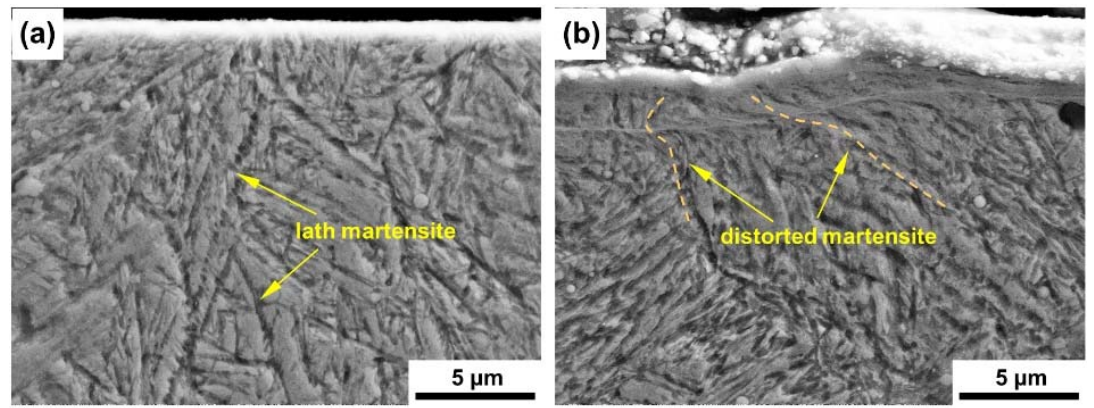

Figure 5. Cont. 
(c)

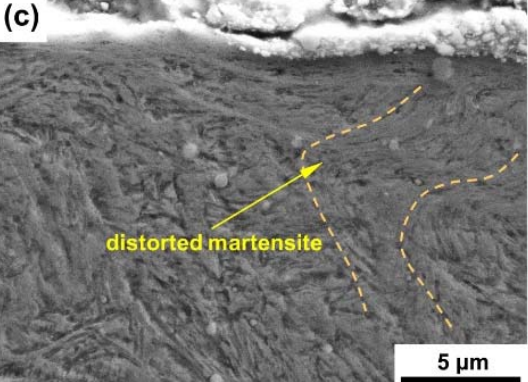

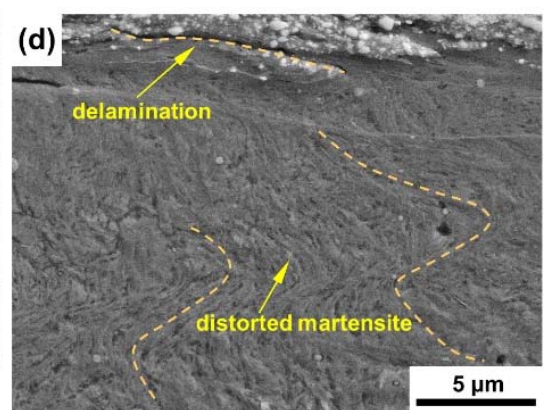

Figure 5. SEM micrographs of cross-sectional microstructure of the M50 steel with different USP durations: (a) $0 \mathrm{~min}$; (b) $1 \mathrm{~min}$; (c) $5 \mathrm{~min}$; (d) $10 \mathrm{~min}$.

To investigate the effect of USP treatment on the microstructure of M50 steel, EBSD tests were performed to analyze the changes in martensite packet diameter, grain boundaries, and KAM distribution. As shown in Figure 6, EBSD scanning was taken from the top surface up to $200 \mu \mathrm{m}$ depth to visually characterize the microstructure refinement effect. The IPF image in Figure 6a shows that the martensite packet diameter is refined after USP treatment. A gradient distribution of microstructure in the depth direction is obtained, and the microstructure in the near-surface region is significantly refined with indistinguishable grain boundaries. The statistical analysis of the divided regions in Figure $6 \mathrm{~d}$ shows that the average martensite packet diameter has a linear relationship with the depth from the surface. The average martensite packet diameter near the surface layer is $0.44 \mu \mathrm{m}$, which is $76 \%$ smaller than that of the untreated samples $(1.83 \mu \mathrm{m})$ in Figure 1 . The thickness of the layer with submicron-grained martensite less than $1 \mu \mathrm{m}$ exceeds $80 \mu \mathrm{m}$ (light yellow background color in Figure 6d). At the depth of $200 \mu \mathrm{m}$ from the surface, the average size of the martensite of the USP treated samples $(1.59 \mu \mathrm{m})$ is still lower than that of the base material, indicating that the depth of surface grain refinement exceeds $200 \mu \mathrm{m}$.
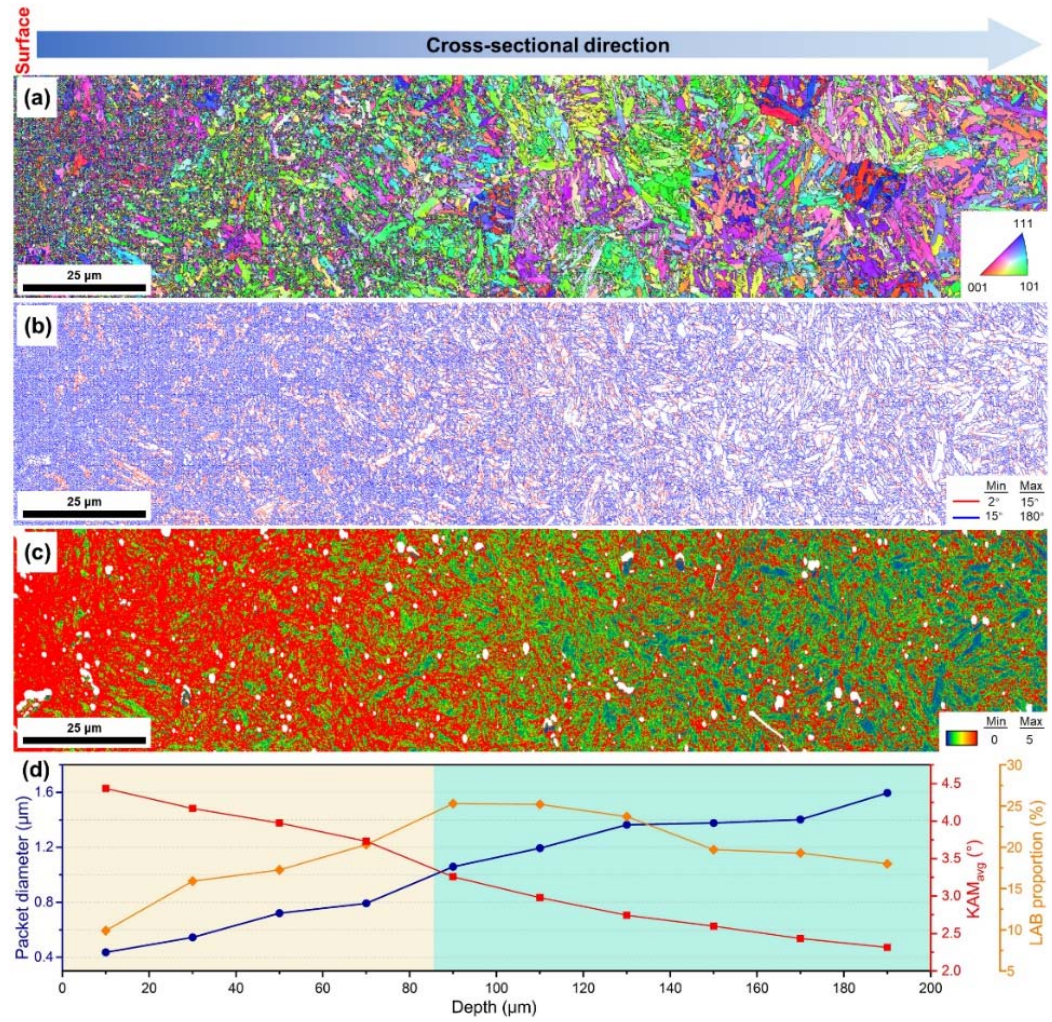

Figure 6. Cross-sectional EBSD images of the M50 steel after 10 min USP treatment: (a) IPF map; (b) grain boundary map; (c) KAM map; (d) statistical results of (a-c). 
Figure $6 \mathrm{~b}$ depicts the grain boundary map of the cross-sectional microstructure. The LABs in the region near the surface are reduced, followed by an increase, but then again decreased (with the increase in depth). The percentage of LABs proportion near the surface region is merely $9.9 \%$, which may be related to the formation of subgrains and large lattice orientation differences. With increasing depth from the surface $(<100 \mu \mathrm{m})$, the orientation difference between grains decreases, leading to a gradual increase in the proportion of LABs. In the depth range of 100-200 $\mu \mathrm{m}$, the LABs proportion decreases with increasing depth, which may be associated with the decreasing of subgrains.

Figure 6c shows the KAM map of the cross-sectional microstructure. Large plastic strain can be observed in the surface layer of the USP treated M50 steel. The average value of KAM near the surface layer is increased to $4.54^{\circ}$, indicating that USP treatment can induce a large plastic strain in the surface layer of M50 steel. Meanwhile, there is a depth gradient effect of plastic strain, the average value of KAM decreases with the depth. Up to the depth of $200 \mu \mathrm{m}$, the average value of KAM is $2.32^{\circ}$, which is still higher than the KAM value of the base material. This indicates that the influence depth of USP on M50 steel exceeds $200 \mu \mathrm{m}$. In addition, the KAM value reflects the content of geometrically necessary dislocations (GNDs) by the following equation [32].

$$
\rho_{G N D}=\frac{2 K A M_{a v g}}{\mu b}
$$

where $K A M_{a v g}$ is the average KAM value of the selected area, $b$ the Burgers vector magnitude $(0.248 \mathrm{~nm}$ for $\mathrm{BCC}$ iron), and $\mu$ the step size. The larger the KAM value, the higher the dislocation density. In the KAM plot, the red color dominates the near-surface region of the cross-section, indicating the high density of dislocation in the near-surface layer of the USP-treated M50 steel. As the KAM value gradually decreases with increasing depth, the dislocation density also decreases.

To investigate the effect of USP treatment of M50 steel at the nanoscale, TEM tests were performed on the base material and USP treated samples, as shown in Figure 7. The TEM observations were conducted at the topmost surface for the 10 min USP treated sample. The HADDF-STEM image in Figure 7a shows that the original microstructure of the M50 steel is mainly coarse lath martensite. After USP treatment, the coarse lath martensite transforms into a finer martensite structure. The width of the original lath martensite is about hundreds of nanometers. After USP treatment, the bright-field and dark-field images (Figure $7 \mathrm{~d}, \mathrm{f}$ ) show that a large number of subgrains are formed inside the original lath martensite. The width of the martensitic subgrains is quite small, some even less than $20 \mathrm{~nm}$. The diffraction spots of the selected area electron diffraction in Figure $7 \mathrm{~d}$ have small arcs, which indicates the deformation and rotation of the subgrain boundaries [33]. 

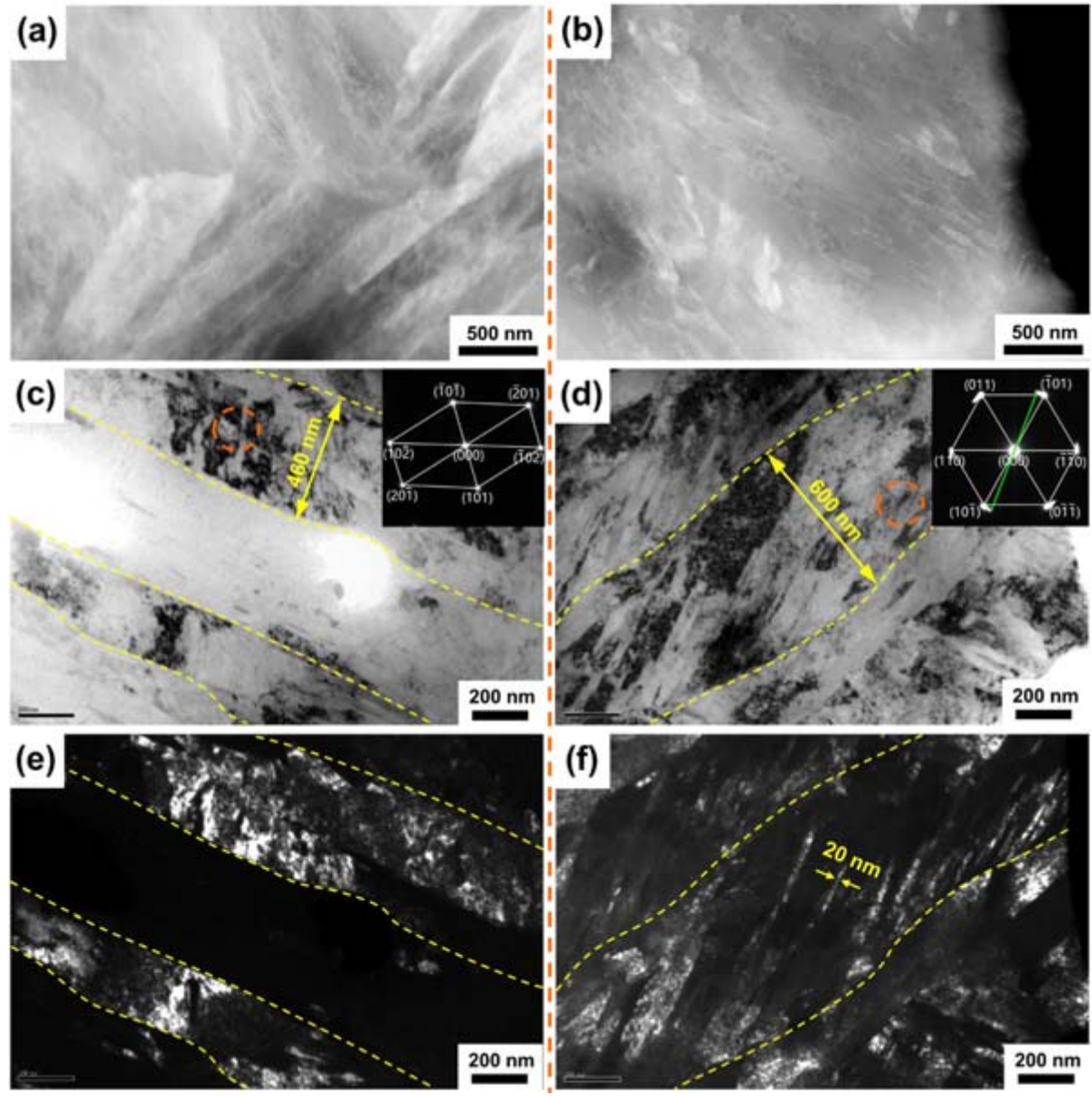

Figure 7. The (a) HADDF-STEM, (c) bright and (e) dark-field images of the base material; the (b) HADDF-STEM, (d) bright, and (f) dark-field images of 10 min USP treated sample at the topmost surface.

\subsection{Microhardness and Residual Stress}

Figure 8 compares the change in Vickers hardness at different depths from the surface of M50 steel with different USP durations. There is little variation in microhardness at different depths for untreated M50 steel at 795 HV. After USP treatment, an ultrastrong surface layer with gradient hardening is obtained. There is a significant increase in microhardness and a gradient along the depth direction. The longer the USP treatment time, the more pronounced the microhardness increase and the deeper the hardening depth. With $10 \mathrm{~min}$ USP treatment, the maximum microhardness of M50 steel has increased to $987 \mathrm{HV}$, which is a $24 \%$ increase relative to the base material, and the hardening depth is around $800 \mu \mathrm{m}$ with 10 min USP treatment. Different from the monotonic decrease in microhardness with depth reported in the literature [26,34,35], the microhardness of USP treated M50 steel first increases and then decreases with increasing depth. This follows with the trend of LABs proportion along the depth direction (Figure 6d).

The introduction of residual compressive stresses can increase the structural stability of metallic materials and improve the resistance to crack expansion. Figure 9 shows the residual stress on the surface of M50 steel treated with different USP durations. Before USP treatment, the original microstructure has a certain residual compressive stress due to the prior QT treatment. After the USP treatment, due to the high-speed continuous impact of the shots, the surface residual compressive stress increased from 427.0 MPa to 1202.8 MPa, which is more than twice the stress in the base material. Additionally, the residual compressive stress tends to increase with a longer USP treatment duration. The 
surface residual compressive stress is consistent with the variation trend of hardness, which is in line with the findings of Zhang et al. [36].

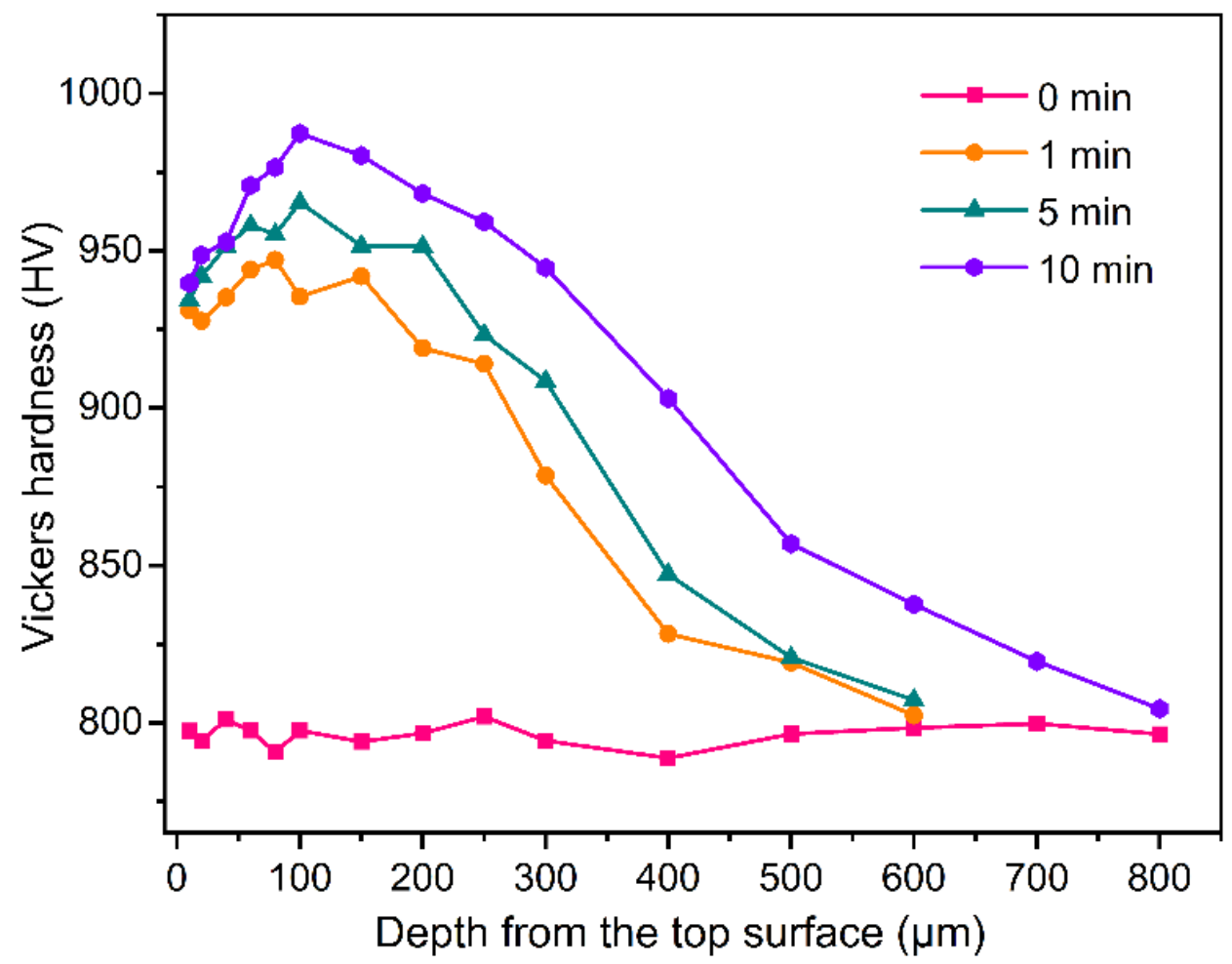

Figure 8. Vickers hardness distribution at different depths from the surface of the M50 steel with different USP durations.

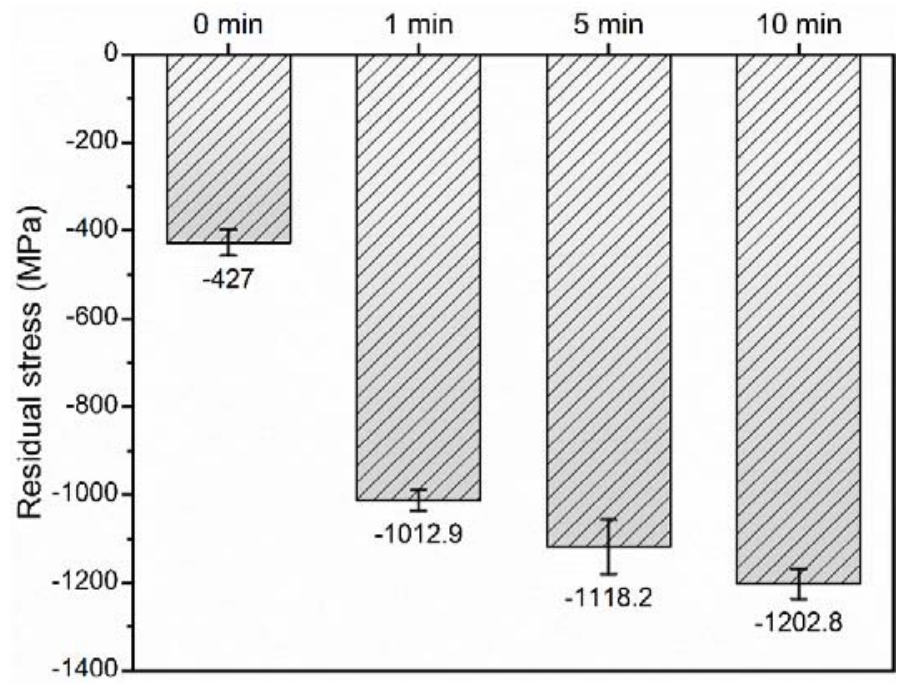

Figure 9. Residual stress after USP treatment.

\subsection{Wear Behavior}

Figure 10a shows the variation of the friction coefficient of USP treated M50 steel as a function of time. Starting from a small value, the friction coefficient stabilizes within the first few minutes at $\sim 0.45$. The effect of USP treatment on the friction coefficient is minimal, and only a slight increase in the friction coefficient of USP treated M50 steel is observed. After $60 \mathrm{~min}$ of dry sliding friction at $300^{\circ} \mathrm{C}$, the section profile of the wear track is shown in Figure 10b. While the depth of the wear track with 1 min of USP treatment is deeper than that of the base material, it is decreased for all other durations. Meanwhile, the width of 
the wear track (Figure 10c) shows that 1 min UPS does not affect the property so much and the width of $1.48 / 1.50 \mathrm{~mm}$ is within the range of experimental errors. For the $10 \mathrm{~min}$ USPtreated sample, the width of the wear track is reduced to $1.28 \mathrm{~mm}$. Figure $10 \mathrm{~d}$ statistically illustrates the variation of friction coefficient and wear rate. The friction coefficient tends to increase slightly with the USP treatment duration, while the wear rate first increases and then decreases with the USP treatment duration. The wear rate is reduced by $50.5 \%$ compared to the base material after 10 min USP treatment.
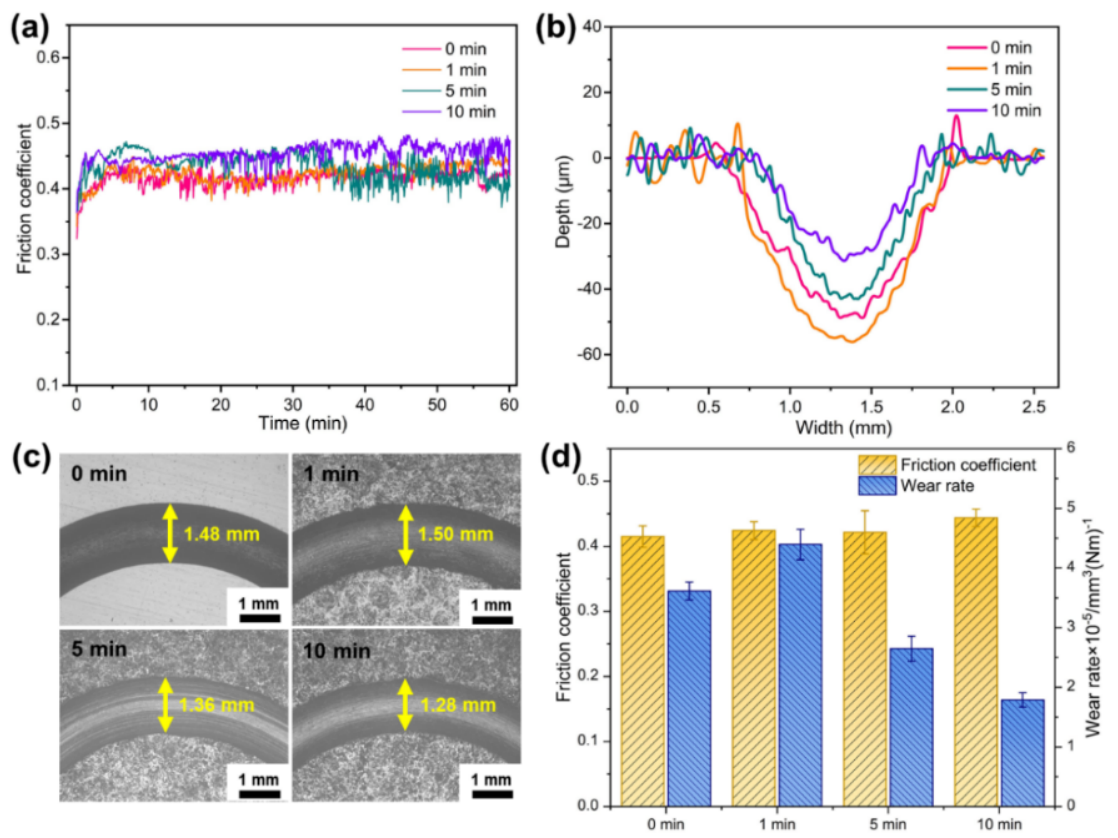

Figure 10. (a) Friction coefficient as a function of wear time; (b) section profile of the wear track; (c) width of wear track; (d) average friction coefficients and wear rates of the M50 steel with different USP durations.

Figure 11 illustrates SEM characterizations of the worn surface of M50 steel with different USP durations. On the worn surface of the base material (Figure 11a), big grooves parallel to the sliding direction and wear debris can be found, which may result from the plowing wear. According to the distributions of the oxygen element of the worn surface (inserted in the image), larger areas of oxide debris are covered on the worn surface, showing that the oxidation is serious for the base material. Whereas, on the worn surface of the USP-treated samples, there is a significant reduction in the size of the grooves and a decrease in the degree of oxidation. Meanwhile, as the USP treatment time increases, the size of the grooves formed during the wear test gradually decreases and the surface oxidation is lower.

To further investigate the effect of USP treatment on the frictional behavior of M50 steel, the cross-sectional microstructure after the wear test was characterized by SEM, as shown in Figure 12. For the base material, significant plastic deformation of the lath martensite is present in the near-surface region $(8.4 \mu \mathrm{m}$ in depth). A possible reason is that during high-temperature friction, the frictional force drives the surface microstructure to deflect along the direction of frictional motion. By leaning the martensite in the horizontal direction, plastic deformation of the surface layer occurs. For the USP-treated samples, the depth of the plastic deformation layer decreases as the USP treatment duration increases (2.1 $\mu \mathrm{m}$ at $10 \mathrm{~min}$ USP treatment). 

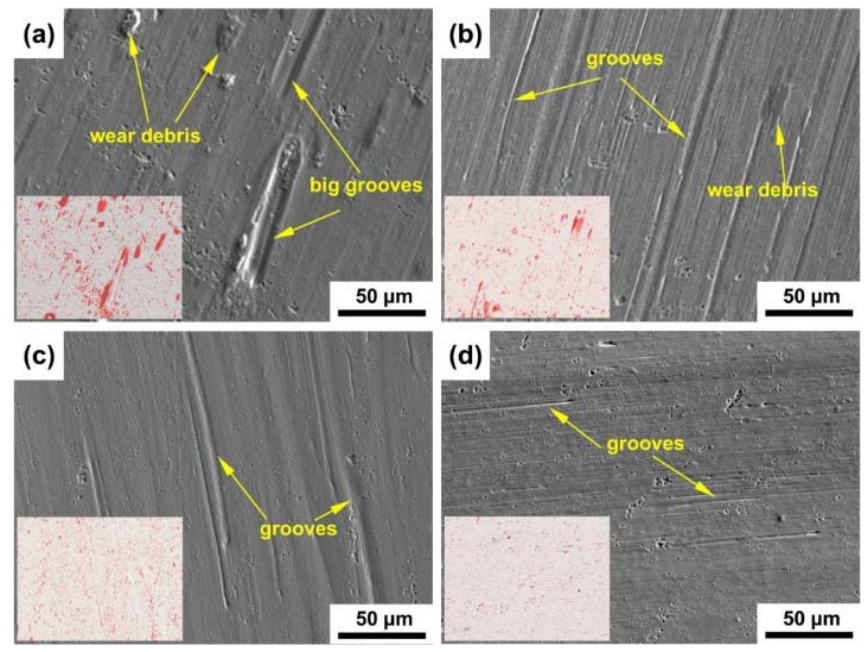

Figure 11. SEM characterizations of the worn surface of M50 steel with different USP durations: (a) $0 \mathrm{~min}$; (b) $1 \mathrm{~min}$; (c) $5 \mathrm{~min}$; (d) $10 \mathrm{~min}$.
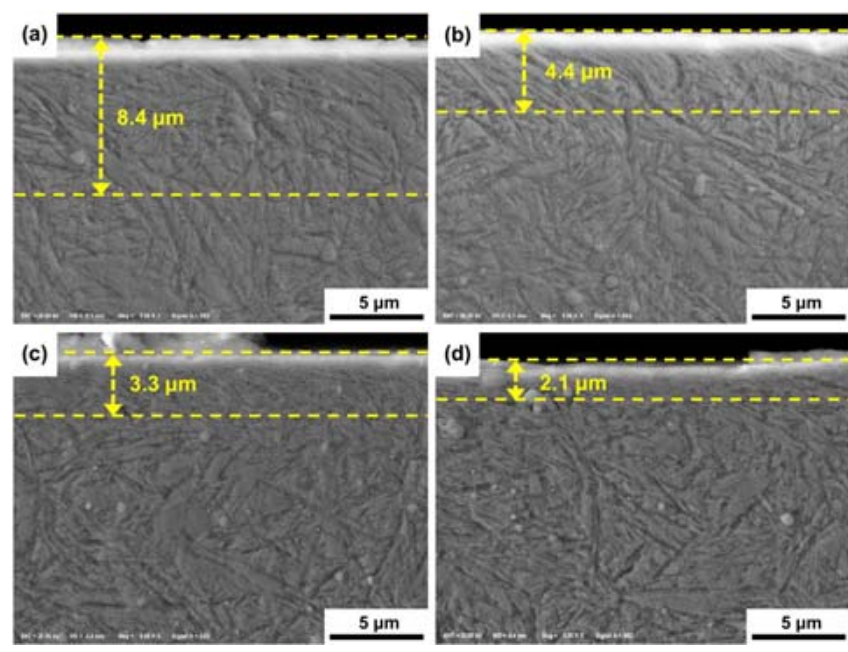

Figure 12. Cross-sectional microstructure after wear test of the M50 steel with different USP durations: (a) $0 \mathrm{~min}$; (b) $1 \mathrm{~min}$; (c) $5 \mathrm{~min}$; (d) $10 \mathrm{~min}$.

\section{Discussion}

\subsection{Microstructure Refinement Mechanism}

A gradient nanograined surface layer was generated in the M50 steel after the USP treatment. Plastic strain-induced grain refinement is closely related to the accumulation of dislocations [37]. The lath martensite of M50 steel base material contains a large number of dislocations as seen in the KAM map in Figure 1. As the surface roughness increases under the continuous USP impact (Figure 3), the strain accumulates. The large plastic strain leads to the accumulation of dislocations. By absorbing dislocations present inside the martensite laths, dislocations could evolve into the LABs with an increase in dislocation density [38]. Then subgrains are formed in the original martensite packet through the interconnection of LABs. Meanwhile, as the plastic strain further increases, the subgrains will rotate and deform to accommodate the increased plastic strain (Figure 7). As LABs may evolve into HABs under large strains [22], the content of small-angle grain boundaries in the near-surface region after USP treatment is low. As a result, the microstructure of M50 steel in the near-surface region is gradually homogenized and refined to nanoscale martensite subgrains under USP treatment. As the degree of strain decreases along the depth, the rotational deformation of the martensitic subgrains decreases, which leads to 
an increase in the proportion of LABs. In deeper regions with smaller strains, the grain refinement effect caused by the accumulation of dislocations gradually weakens.

\subsection{Hardening Mechanism}

The significant increase in hardness of M50 steel after USP treatment can be explained by two mechanisms. On one hand, the microstructure of the USP-treated M50 steel is greatly refined and distorted, which hardens the steel. According to the Hall-Petch equation [39],

$$
H=H_{0}+\frac{k_{H}}{\sqrt{d}}
$$

where $H$ is the surface hardness, $k_{H}$ a constant for a given material, $H_{0}$ the appropriate constant associated with the hardness measurements, and $d$ the average diameter of the lath martensite. After USP treatment, the lath martensite of the surface layer is transformed into subgrains with nanometer and submicron size. The refinement of lath martensite plays a considerable role in improving the surface hardness of M50 steel. On the other hand, the dislocation density of the M50 steel increases significantly after the USP treatment. Kocks et al. have reported that the storage of dislocations causes work hardening in crystals [40]. Since lath martensite has a BCT structure, dislocations do not easily move during deformation, and higher hardness could be obtained by dislocation storage. In short, the distorted martensite subgrains and high dislocation density in the USP-treated M50 steel contribute to the increase of surface hardness.

\subsection{Wear Mechanism}

Wear resistance is related to a variety of mechanical properties of metals, of which hardness is one of the most important. According to classical friction theory, the wear volume is proportional to the actual contact area during wear as determined by the hardness of the material [41].

$$
\Delta V=f P L / H
$$

where $f$ is the friction coefficient, $P$ the applied load, $L$ the sliding distance, and $H$ the hardness. This relation applies to both adhesive and abrasive wear conditions. The experimental results indicate that the enhanced wear resistance is correlated with the significant increase of hardness induced by USP treatment. Simultaneously, the high residual compressive stress introduced by USP also contributes to the wear resistance, because the residual compressive stress in the hardening layer can prevent plastic deformation and retard the development of microcracks during wear tests [42]. The wear surface morphology in Figure 11 shows that the groove depth decreases and the plowing wear degree weakens with high residual compressive stress. Furthermore, the USP-treated samples show a reduction of oxidation on the worn surface. Due to the ultrastrong surface layer with gradient nanograin formed by USP treatment, fewer hard oxidized wear debris adheres to the worn surface during the wear process. Thus, the degree of abrasive wear is reduced, resulting in smaller grooves on the worn surface, as well as lower oxidation. Li's study suggests that nanometals may have a lower coefficient of friction than coarse crystals because of their higher hardness [43]. This phenomenon has not been observed in this work, which may be due to the increase in surface roughness after USP treatment. The effect of high hardness in reducing the friction coefficient is offset by the poor surface morphology so that the friction coefficient of the USP treated M50 steel is slightly increased.

Based on the above observations, the functional mechanism of USP treatment on the wear properties of M50 steel during the sliding friction has been proposed in Figure 13. As shown in Figures 12 and 13a, the cross-sectional microstructure of worn M50 steel is mainly composed of lath martensite and alloy carbides. Due to the low hardness and low residual compressive stress of the base material, a thick plastic deformation layer is formed during the wear process. On the surface of the wear track, there are many big grooves and oxidized wear debris (Figure 12). For the USP treated M50 steel shown in Figure 13b, as an 
ultrastrong surface layer with gradient nanograin is obtained, the thickness of the plastic deformation layer is decreased. This is mainly because of the fine microstructure of high hardness which reduces the frictional strain. At the same time, the wear surface is relatively smooth with small grooves distributed evenly on the wear track surface, and the oxidation degree is also significantly reduced (Figure 11). Therefore, the USP treatment can help to change the wear mechanism of M50 steel from severe plowing wear and oxidative wear to mild plowing wear.

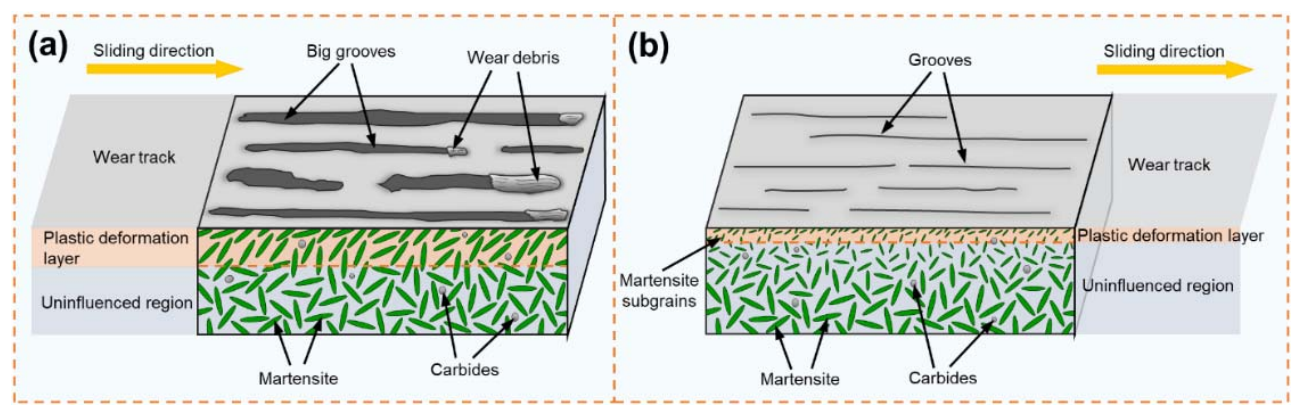

Figure 13. Schematic description of the wear mechanism influenced by USP treatment: (a) without USP treatment; (b) after USP treatment.

\section{Conclusions}

In this work, we successfully fabricated ultrastrong M50 bearing steel with gradient nanostructure by ultrasonic shot peening technology. The effects of USP on the surface integrity, microstructure evolution, and wear behaviors of the M50 steel have been investigated, and quantitative characterization of the USP treated M50 steel has been provided. Conclusions can be drawn as follows:

(a) USP treatment can increase the surface roughness of M50 steel, and the surface roughness increases with the duration of USP treatment (from Sa $2.53 \mu \mathrm{m}$ at $1 \mathrm{~min}$ to Sa $3.31 \mu \mathrm{m}$ at $10 \mathrm{~min}$ ).

(b) The dislocation density of the M50 steel has been greatly increased after USP treatment. A gradient nanograined surface layer with a thickness of more than $200 \mu \mathrm{m}$ was fabricated and the thickness of the lath martensite has refined down to 20 600 nm. The high KAM value proves the presence of high dislocation density in the nearsurface layer in the USP-treated M50 steel, and the dislocation density gradually decreases with increasing depth.

(c) The surface residual compressive stress is increased from 427.0 MPa to 1202.8 MPa. Additionally, the maximum hardness of the USP-treated M50 bearing steel is increased by $24 \%$ (from $795 \mathrm{HV}$ to $987 \mathrm{HV}$ ) at a depth of around $100 \mu \mathrm{m}$. Beyond $100 \mu \mathrm{m}$, the hardness of USP treated M50 steel decreases with increasing depth. The trend follows that of the LABs proportion along the depth direction.

(d) The wear rate of the USP-treated M50 steel is reduced by $50.4 \%$ under sliding conditions compared to that of the untreated M50 steel, due to the ultrastrong surface layer with gradient nanograin. As the duration of USP treatment increases, the wear mechanism of the gradient nanostructured M50 bearing steel changes from oxidative wear and severe plowing wear to mild plowing wear, and the thickness of the plastic deformation layer generated during the friction process is reduced.

This study provides an effective surface treatment method to improve the wear resistance of high-strength M50 steel. With a sufficiently deep strengthening layer, the USP treatment method is expected to be applied to the practical production of bearings.

Author Contributions: Conceptualization, D.Q. and F.Y.; methodology, D.Q.; software, H.W.; validation, Z.D. and F.W.; formal analysis, Z.D.; investigation, Z.D. and F.W.; resources, J.C.; data curation, Z.D.; writing—original draft preparation, Z.D. and F.W.; writing—review and editing, X.W. and S.H.; 
visualization, Z.D.; supervision, D.Q.; project administration, D.Q.; funding acquisition, D.Q. and F.Y. All authors have read and agreed to the published version of the manuscript.

Funding: This work was financially supported by the National Key R\&D Program of China (No 2020YFA0714900), National Natural Science Foundation of China (No.51875426), Fundamental Research Funds for the Central Universities (WUT: 2020IVA020, 2021IVA027B), Innovative Research Team Development Program of Ministry of Education of China (No.IRT_17R83), and Overseas Expertise Introduction Project for Discipline Innovation (B17034).

Conflicts of Interest: The authors declare no conflict of interest.

$\begin{array}{ll}\text { Nomenclature } \\ \text { HABs } & \text { High angle boundaries } \\ \text { IPF } & \text { Inverse pole figure } \\ \text { KAM } & \text { Kernel average misorientation } \\ \text { LABs } & \text { Low angle boundaries } \\ \text { POD } & \text { Pin-on-disk } \\ \text { QT } & \text { Quenching and tempering } \\ \text { SP } & \text { Shot peening } \\ \text { USP } & \text { Ultrasonic shot peening }\end{array}$

\section{References}

1. Zaretsky, E.V. Rolling bearing steels-a technical and historical perspective. Mater. Sci. Technol. 2012, 28, 58-69. [CrossRef]

2. Bhadeshia, H.K.D.H. Steels for bearings. Prog. Mater. Sci. 2012, 57, 268-435. [CrossRef]

3. Babutskyi, A.; Chrysanthou, A.; Zhao, C. Effect of pulsed magnetic field pre-treatment of AISI 52100 steel on the coefficient of sliding friction and wear in pin-on-disk tests. Friction 2014, 2, 310-316. [CrossRef]

4. Kovacı, H.; Hacısalihoğlu, İ.; Yetim, A.F.; Çelik, A. Effects of shot peening pre-treatment and plasma nitriding parameters on the structural, mechanical and tribological properties of AISI 4140 low-alloy steel. Surf. Coat. Technol. 2019, 358, 256-265. [CrossRef]

5. Yan, M.F.; Zhang, C.S.; Sun, Z. Study on depth-related microstructure and wear property of rare earth nitrocarburized layer of M50NiL steel. Appl. Surf. Sci. 2014, 289, 370-377. [CrossRef]

6. Yan, M.F.; Chen, B.F.; Li, B. Microstructure and mechanical properties from an attractive combination of plasma nitriding and secondary hardening of M50 steel. Appl. Surf. Sci. 2018, 455, 1-7. [CrossRef]

7. Soady, K.A.; Mellor, B.G.; West, G.D.; Harrison, G.; Morris, A.; Reed, P.A.S. Evaluating surface deformation and near surface strain hardening resulting from shot peening a tempered martensitic steel and application to low cycle fatigue. Int. J. Fatigue 2013, 54, 106-117. [CrossRef]

8. Gopi, R.; Saravanan, I.; Devaraju, A.; Loganathan, G.B. Investigation of shot peening process on stainless steel and its effects for tribological applications. Mater. Today Proc. 2020, 22, 580-584. [CrossRef]

9. Shen, Y.; Moghadam, S.M.; Sadeghi, F.; Paulson, K.; Trice, R.W. Effect of retained austenite-Compressive residual stresses on rolling contact fatigue life of carburized AISI 8620 steel. Int. J. Fatigue 2015, 75, 135-144. [CrossRef]

10. Macek, W. Fracture Areas Quantitative Investigating of Bending-Torsion Fatigued Low-Alloy High-Strength Steel. Metals 2021, 11, 1620. [CrossRef]

11. Masoudi Nejad, R.; Berto, F. Fatigue fracture and fatigue life assessment of railway wheel using non-linear model for fatigue crack growth. Int. J. Fatigue 2021, 153, 106516. [CrossRef]

12. Polonsky, I.A.; Chang, T.P.; Keer, L.M.; Sproul, W.D. An analysis of the effect of hard coatings on near-surface rolling contact fatigue initiation induced by surface roughness. Wear 1997, 208, 204-219. [CrossRef]

13. Otsuka, A.; Fujii, Y.; Maeda, K. A new testing method to obtain mode 2 fatigue crack growth characteristics of hard materials. Fatigue Fract. Eng. Mater. Struct. 2004, 27, 203-212. [CrossRef]

14. Wang, F.; Qian, D.; Hua, L.; Lu, X. The effect of prior cold rolling on the carbide dissolution, precipitation and dry wear behaviors of M50 bearing steel. Tribol. Int. 2019, 132, 253-264. [CrossRef]

15. Yasnii, P.V.; Marushchak, P.O.; Hlad'o, V.B.; Nikiforov, Y.M.; Kovalyuk, B.P. Influence of laser shock-wave treatment on the impact toughness of heat-resistant steels. Mater. Sci. 2010, 46, 425-429. [CrossRef]

16. Yin, M.-G.; Cai, Z.-B.; Li, Z.-Y.; Zhou, Z.-R.; Wang, W.-J.; He, W.-F. Improving impact wear resistance of Ti-6Al-4V alloy treated by laser shock peening. Trans. Nonferrous Met. Soc. China 2019, 29, 1439-1448. [CrossRef]

17. Yin, F.; Hu, S.; Xu, R.; Xiang, S.; Hua, L.; Cheng, G.J. Ultrastrong medium entropy alloy with simultaneous strength-ductility improvement via heterogeneous nanocrystalline structures. Mater. Sci. Eng. A 2021, 823, 141631. [CrossRef]

18. Yin, F.; Hu, S.; Xu, R.; Han, X.; Qian, D.; Wei, W.; Hua, L.; Zhao, K. Strain rate sensitivity of the ultrastrong gradient nanocrystalline 316L stainless steel and its rate-dependent modeling at nanoscale. Int. J. Plast. 2020, 129, 102696. [CrossRef]

19. Yin, F.; Rakita, M.; Hu, S.; Han, Q. Overview of ultrasonic shot peening. Surf. Eng. 2017, 33, 651-666. [CrossRef] 
20. Yin, F.; Hua, L.; Wang, X.; Rakita, M.; Han, Q. Numerical modelling and experimental approach for surface morphology evaluation during ultrasonic shot peening. Comput. Mater. Sci. 2014, 92, 28-35. [CrossRef]

21. Chen, H.; Guan, Y.; Zhu, L.; Li, Y.; Zhai, J.; Lin, J. Effects of ultrasonic shot peening process parameters on nanocrystalline and mechanical properties of pure copper surface. Mater. Chem. Phys. 2021, 259, 124025. [CrossRef]

22. Wu, X.; Tao, N.; Hong, Y.; Xu, B.; Lu, J.; Lu, K. Microstructure and evolution of mechanically-induced ultrafine grain in surface layer of AL-alloy subjected to USSP. Acta Mater. 2002, 50, 2075-2084. [CrossRef]

23. Yin, F.; Cheng, G.J.; Xu, R.; Zhao, K.; Li, Q.; Jian, J.; Hu, S.; Sun, S.; An, L.; Han, Q. Ultrastrong nanocrystalline stainless steel and its Hall-Petch relationship in the nanoscale. Scr. Mater. 2018, 155, 26-31. [CrossRef]

24. Bagherifard, S.; Slawik, S.; Fernández-Pariente, I.; Pauly, C.; Mücklich, F.; Guagliano, M. Nanoscale surface modification of AISI 316L stainless steel by severe shot peening. Mater. Des. 2016, 102, 68-77. [CrossRef]

25. Yin, F.; Liu, Y.; Xu, R.; Zhao, K.; Partin, A.; Han, Q. Nanograined surface fabricated on the pure copper by ultrasonic shot peening and an energy-density based criterion for peening intensity quantification. J. Manuf. Process. 2018, 32, 656-663. [CrossRef]

26. Karimbaev, R.; Pyun, Y.-S.; Maleki, E.; Unal, O.; Amanov, A. An improvement in fatigue behavior of AISI 4340 steel by shot peening and ultrasonic nanocrystal surface modification. Mater. Sci. Eng. A 2020, 791, 139752. [CrossRef]

27. Sun, Q.; Han, Q.; Xu, R.; Zhao, K.; Li, J. Localized corrosion behaviour of AA7150 after ultrasonic shot peening: Corrosion depth vs. impact energy. Corros. Sci. 2018, 130, 218-230. [CrossRef]

28. Zou, Y.; Li, J.; Liu, X.; He, T.; Lu, J.; Li, D.; Li, Y. Effect of multiple ultrasonic nanocrystal surface modification on surface integrity and wear property of DZ2 axle steel. Surf. Coat. Technol. 2021, 412, 127012. [CrossRef]

29. Archard, J.F. Contact and rubbing of flat surfaces. J. Appl. Phys. 1953, 24, 981-988. [CrossRef]

30. Karademir, I.; Celik, M.B.; Husem, F.; Maleki, E.; Amanov, A.; Unal, O. Effects of constrained groove pressing, severe shot peening and ultrasonic nanocrystal surface modification on microstructure and mechanical behavior of S500MC high strength low alloy automotive steel. Appl. Surf. Sci. 2021, 538, 147935. [CrossRef]

31. Patterson, A.L. The Scherrer Formula for X-Ray Particle Size Determination. Phys. Rev. 1939, 56, 978. [CrossRef]

32. Shamsujjoha, M. Evolution of microstructures, dislocation density and arrangement during deformation of low carbon lath martensitic steels. Mater. Sci. Eng. A 2020, 776, 139039. [CrossRef]

33. Wu, S.; Fan, K.; Jiang, P.; Chen, S. Grain refinement of pure Ti during plastic deformation. Mater. Sci. Eng. A 2010, 527, 6917-6921. [CrossRef]

34. Lai, F.; Qu, S.; Lewis, R.; Slatter, T.; Fu, W.; Li, X. The influence of ultrasonic surface rolling on the fatigue and wear properties of 23-8N engine valve steel. Int. J. Fatigue 2019, 125, 299-313. [CrossRef]

35. Zhang, J.; Li, W.; Wang, H.; Song, Q.; Lu, L.; Wang, W.; Liu, Z. A comparison of the effects of traditional shot peening and micro-shot peening on the scuffing resistance of carburized and quenched gear steel. Wear 2016, 368-369, 253-257. [CrossRef]

36. Zhang, Y.; Lai, F.; Qu, S.; Ji, V.; Liu, H.; Li, X. Effect of shot peening on residual stress distribution and tribological behaviors of 17Cr2Ni2MoVNb steel. Surf. Coat. Technol. 2020, 386, 125497. [CrossRef]

37. Sun, H.Q.; Shi, Y.N.; Zhang, M.X.; Lu, K. Plastic strain-induced grain refinement in the nanometer scale in a Mg alloy. Acta Mater. 2007, 55, 975-982. [CrossRef]

38. Schouwenaars, R.; Seefeldt, M.; Houtte, P.V. The stress field of an array of parallel dislocation pile-ups: Implications for grain boundary hardening and excess dislocation distributions. Acta Mater. 2010, 58, 4344-4353. [CrossRef]

39. Amanov, A.; Cho, I.S.; Pyoun, Y.S.; Lee, C.S.; Park, I.G. Micro-dimpled surface by ultrasonic nanocrystal surface modification and its tribological effects. Wear 2012, 286-287, 136-144. [CrossRef]

40. Kocks, U.F.; Mecking, H. Physics and phenomenology of strain hardening: The FCC case. Prog. Mater. Sci. 2003, 48, 171-273. [CrossRef]

41. Jia, K.; Fischer, T.E. Sliding wear of conventional and nanostructured cemented carbides. Wear 1997, 203, 310-318. [CrossRef]

42. Cao, Y.J.; Sun, J.Q.; Ma, F.; Chen, Y.Y.; Cheng, X.Z.; Gao, X.; Xie, K. Effect of the microstructure and residual stress on tribological behavior of induction hardened GCr15 steel. Tribol. Int. 2017, 115, 108-115. [CrossRef]

43. Li, G.; Chen, J.; Guan, D. Friction and wear behaviors of nanocrystalline surface layer of medium carbon steel. Tribol. Int. 2010, 43, 2216-2221. [CrossRef] 